ORIGINAL RESEARCH ARTICLE

\title{
Trends in Health Facility Births in sub-Saharan Africa: An Analysis of Lessons Learned under the Millennium Development Goal Framework
}

\author{
Ifeyinwa E. Udo ${ }^{1}$ and Henry V. Doctor ${ }^{2}$ \\ Yale University School of Public Health, Center for Interdisciplinary Research on AIDS, 135 College Street, New Haven, CT \\ 06520, USA ${ }^{1}$; World Health Organization, Regional Office for the Eastern Mediterranean, Informatcion, Evidence and Research, \\ Health Information and Statistics, Nasr City, Cairo 11371, Egypt ${ }^{2}$
}

*For Correspondence: E-mail: ifyunad@yahoo.com; Phone: +1-443-831-1098

\begin{abstract}
Sub-Saharan Africa (SSA) has the highest maternal and under-5 mortality rates as well as low facility births, with a high percentage of births occurring in the absence of skilled personnel. We examine trends in health facility births in SSA by geographic areas (urban-rural) and regions; and also the correlation between health facility birth and neonatal mortality rate (NMR). Data come from Demographic and Health Surveys (27 countries), conducted between 1990 and 2014. Median health facility births, urban-rural gaps, and regional variations in health facility births between initial (1990) and latest (2014) surveys were calculated. The median health facility birth increased from $44 \%$ at initial survey to $57 \%$ at the latest survey. Rural areas had a higher percentage increase in health facility births between initial and latest surveys (16\%) than urban areas (6\%) with a $2 \%$ overall gap reduction between initial and latest surveys. Health facility births were inversely associated with NMR at initial $\left(\mathrm{R}^{2}=0.20, \mathrm{p}=0.019\right)$ and latest $\left(\mathrm{R}^{2}=0.26, \mathrm{p}=0.007\right)$ surveys. To achieve the Sustainable Development Goal target of reducing neonatal mortality, policies should particularly focus on bringing rural areas on par with urban areas. (Afr J Reprod Health 2016 (Special Edition); 20[3]: 108-117).
\end{abstract}

Keywords: Skilled birth attendants, maternal mortality, infant mortality, neonatal mortality, health facility birth.

\section{Résumé}

L'Afrique sub-saharienne (ASS) a les taux de mortalité maternelle et de moins de 5 ans les plus hauts, ainsi que les faible niveau de naissances dans des établissements de santé, avec un pourcentage élevé de naissances survenues en l'absence de personnel qualifié. Nous examinons les tendances des naissances dans des établissements de santé en Afrique subsaharienne par zones géographiques (urbain-rural) et les régions; et aussi la corrélation entre la naissance dans les 'établissements de santé et le taux de mortalité néonatale (TMN). Les données proviennent des Enquêtes démographiques et de santé (27 pays), réalisées entre 1990 et 2014. Les naissances qui ont lieu dans les établissements de santé médian, les lacunes urbaines et rurales, et les variations régionales des naissances dans des établissements de santé entre les enquêtes initiales (1990) et les dernières (2014) ont été calculées. La naissance dans des établissements de santé médians est passée de $44 \%$ au départ à $57 \%$ au dernier sondage. Les zones rurales ont une plus forte augmentation en pourcentage des naissances dans un établissement de santé entre l'enquête initiale et la dernière (16\%) qu'en milieu urbain $(6 \%)$, avec une réduction globale de l'écart de $2 \%$ entre l'enquête initiale et les dernières enquêtes. Les naissances dans les établissements de santé étaient inversement associées à TMN dans les enquêtes initiales $(\mathrm{R} 2=0,20, \mathrm{p}=0,019)$ et les dernières $(\mathrm{R} 2=0,26, \mathrm{p}=0,007)$ enquêtes. Pour atteindre l'Objectif du développement durable visant à réduire la mortalité néonatale, les politiques devraient particulièrement mettre les régions rurales et les régions urbaines sur le même niveau. (Afr J Reprod Health 2016 (Edition Spéciale); 20[3]: 108-117).

Mots-clés: accoucheuses qualifiées, mortalité maternelle, mortalité infantile, mortalité néonatale, naissance dans des établissements de santé

\section{Introduction}

Maternal mortality ratio (MMR) has been on the decline since 1990. However, most of the reduction took place since 2000 after the international community adopted the Millennium Development Goals (MDGs) ${ }^{1}$. The adoption of the MGDs led to increased efforts by the United Nations Members States to improve the well-being of mothers and children by promoting, among other things, childbirth under the care and supervision of professionally trained birth personnel such as doctors, mid wives and nurses who are for the most part, accessible in health facilities. With the exception of Sub-Saharan Africa (SSA), the rates of births attended by skilled personnel in developing countries have shown impressive increases since the mid-1990s, 


\section{Udo \& Doctor}

with majority of the births occurring in health facilities $^{2}$. In $2014,71 \%$ of births globally were attended by skilled personnel compared to $59 \%$ in $1990^{3,4}$. Several studies have and continue to examine factors associated with maternal mortality, especially in SSA, where the rates are extremely high. These studies have shown among other things, that increasing access to maternal health services including birth under the supervision of skilled personnel, is associated with better maternal outcomes ${ }^{5,6,7}$. Given these, many programs and interventions have been put in place to increase access to and utilization of maternal health services. While these are invaluable measures to take, we must not lose sight of newborn health and survival. Neonatal mortality rate (NMR), although having declined impressively between 1990 and 2015, remains a global health problem and a major contributor to the high global infant mortality rate (IMR) . Globally, about $36 \%$ of neonatal deaths are due to infections whereas preterm birth complications and birth asphyxia account for $28 \%$ and $23 \%$, respectively ${ }^{9}$. Between 1990 and 2015, global NMR reduced from 33 deaths to 19 deaths per 1,000 live births. This decline is slower than that observed for under-5 mortality making neonatal mortality a large contributor to under-5 deaths globally ${ }^{8}$.

In SSA, deaths of newborns during birth and in the first month of life are also largely caused by preventable infectious diseases ${ }^{10,11}$. These causes of death have taken a toll on NMRs in SSA which currently lags behind many countries, and carries about half of the burden of the world's under-5 mortality (3 million in 2015). SSA has the highest risk of neonatal deaths and is also among the regions showing the least progress in reducing $\mathrm{NMR}^{4,6}$. Many neonatal deaths can be averted by interventions that address the needs of women and infants, paying particular attention to care around the time of birth. Some studies have shown that the newborns delivered at home, whose deliveries are not supervised by skilled personnel, are more likely to develop infections - the leading cause of neonatal deaths in $\mathrm{SSA}^{12-14}$, yet about $60 \%$ (18 million) of women in SSA give birth unattended at
Trends in Health Facility Births in Africa

Home15-17. These infections are mostly caused by the absence of sterilized birth conditions which are more feasible and attainable within the confines of a health facility.

Extant research has shown that infants whose mothers attend antenatal care and are delivered in health facilities have better outcomes. These studies also show that women who attend antenatal care are more likely to deliver in health facilities and to continue to utilize postnatal care services than women who do not attend antenatal care $^{18-20}$. Postnatal care services ensures that newborns get proper care in the period immediately following delivery which is when newborns are at highest risk of dying. Skilled care at birth and in the short time following birth is for the most part, accessible through delivery in health facilities, and has been proven to save the lives of many mothers and babies ${ }^{21}$. Increasing the chances of delivering in health facilities among women in SSA is a plausible way to reduce child mortality, particularly the death of newborns.

Taken together, while remarkable progress has been made with MGD 5 regarding attaining two-thirds reduction in infant mortality, the target has not been reached globally. Although SSA, has shown tremendous progress in increasing child survival, it still lags behind many regions and countries continue to experience low skilled birth attendance due to low facility births as well as great disparity between the urban and the rural areas and among regions ${ }^{8,22}$. Given the wealth of evidence on the beneficial effect of facility births on maternal and neonatal outcomes, it is imperative to examine how SSA has fared over the years with respect to facility births, how much change has occurred (regionally and between urban and rural areas), and the important lessons learned to guide future actions. It is also equally important to understand how facility births relate to neonatal mortality. These are important to understand as countries move on with action plans towards achieving the SDGs. The current study addresses this knowledge gap by i) Showing trends in health facility births in SSA by urban-rural areas and by region; and ii) Examining the correlation between health facility births and NMR 
in SSA.

\section{Methods}

\section{Data}

Data come from the Demographic and Health Surveys (DHS) conducted between 1990 and 2014 which include various socio-demographic and health indicators including neonatal mortality, births attended by skilled health personnel and maternal mortality ratios (MMRs - for selected surveys). The data are publicly available online through the DHS STATCompiler (www.stat compiler.com), which allows users to make custom tables based on hundreds of sociodemographic and health indicators spanning at least 80 countries. As of September 2015, the DHS database had 330 surveys of which 133 surveys were in SSA. Of the 133 SSA surveys, 10 had one single survey. Our study consist of data from 27 countries (10 in Western Africa; 5 in Middle Africa; 10 in Eastern Africa; 2 in Southern Africa) that had the earliest and most recent surveys $(n=54)$ with births attended by skilled health personnel provided by region or country and type of residence (rural and urban). Using earliest and most recent surveys allows us to focus on a reasonable length of time in order to observe meaningful changes. Time intervals between the two surveys across the 27 countries ranged from 5 to 23 years, averaging 13.8 years of observation time. The interquartile range was between 7 and 21 years implying that half of the surveys were clustered within time interval of 14 years (Table $1)$.

DHS data, as with many other large-scale survey data, are problematic, however. They are associated with sampling variability of the estimates and non-sampling errors. For example, non-sampling errors are a function of the completeness with which women recall and report child deaths, the accuracy of the date of birth information reported by the mother for living children, and the accuracy of the age at death information given by the mother for the deceased children. Nevertheless, demographic techniques are available to overcome these challenges and lead to estimates or indicators which many countries in the less developed world and SSA in particular can use for health policy planning, implementation, and monitoring ${ }^{16}$.

Table 1: Countries and Demographic and Health Surveys included in the Analysis of Facility Births for sub-Saharan Africa.

\begin{tabular}{|c|c|c|c|}
\hline Country & $\begin{array}{l}\text { Initial } \\
\text { survey }\end{array}$ & $\begin{array}{l}\text { Latest } \\
\text { survey }\end{array}$ & $\begin{array}{l}\text { Observa- } \\
\text { tion time }\end{array}$ \\
\hline \multicolumn{4}{|l|}{ Western Africa } \\
\hline Benin & 2001 & 2011-2012 & 11 \\
\hline Burkina Faso & 1993 & 2010 & 17 \\
\hline Ghana & 1998 & 2008 & 10 \\
\hline Guinea & 1999 & 2012 & 13 \\
\hline Liberia & 2007 & 2013 & 6 \\
\hline Mali & 2001 & $2012-13$ & 12 \\
\hline Niger & 1992 & 2012 & 20 \\
\hline Nigeria & 1990 & 2013 & 23 \\
\hline Senegal & 1993 & 2014 & 21 \\
\hline Sierra Leone & 2008 & 2013 & 5 \\
\hline \multicolumn{4}{|l|}{ Middle Africa } \\
\hline Cameroon & 1991 & 2011 & 20 \\
\hline Chad & $1996-97$ & 2004 & 7 \\
\hline Congo & 2005 & 2011-12 & \\
\hline (Brazzaville) & & & 7 \\
\hline Gabon & 2000 & 2012 & 12 \\
\hline Congo DRC & 2007 & $2013-14$ & 7 \\
\hline \multicolumn{4}{|l|}{ Eastern Africa } \\
\hline Ethiopia & 2000 & 2011 & 11 \\
\hline Kenya & 1993 & 2008 & 15 \\
\hline Madagascar & 1992 & 2008-09 & 17 \\
\hline Malawi & 1992 & 2010 & 18 \\
\hline Mozambique & 2003 & 2011 & 8 \\
\hline Rwanda & 1992 & 2010 & 18 \\
\hline Tanzania & 1992 & 2010 & 18 \\
\hline Uganda & 1995 & 2011 & 16 \\
\hline Zambia & 1992 & 2013-14 & 22 \\
\hline Zimbabwe & 1999 & 2010-2011 & 12 \\
\hline \multicolumn{4}{|l|}{ Southern Africa } \\
\hline Lesotho & 2004 & 2009 & 5 \\
\hline Namibia & 1992 & 2013 & 21 \\
\hline Mean $(n=27)$ & - & - & 13.8 \\
\hline Median $(n=27)$ & - & - & 13.0 \\
\hline
\end{tabular}

Notes: *Observation time calculated based on the upper bound of the year. For example, the 2010-2011 year uses 2011 as the end point.

\section{Variables}

The main variable of interest was health facility births, defined as the percent of most recent births occurring within five years prior to the survey and that were delivered in a health facility. Our independent variable was residence of the women of reproductive age at the time of the interview (urban-rural) and neonatal mortality rate (NMR) defined as the probability of dying within the first month of life, and expressed per 1,000 live births. 
Figure 1: Box and Whisker Plot Showing Percentage of Facility Births at Initial and Latest Surveys for 27 subSaharan African Countries

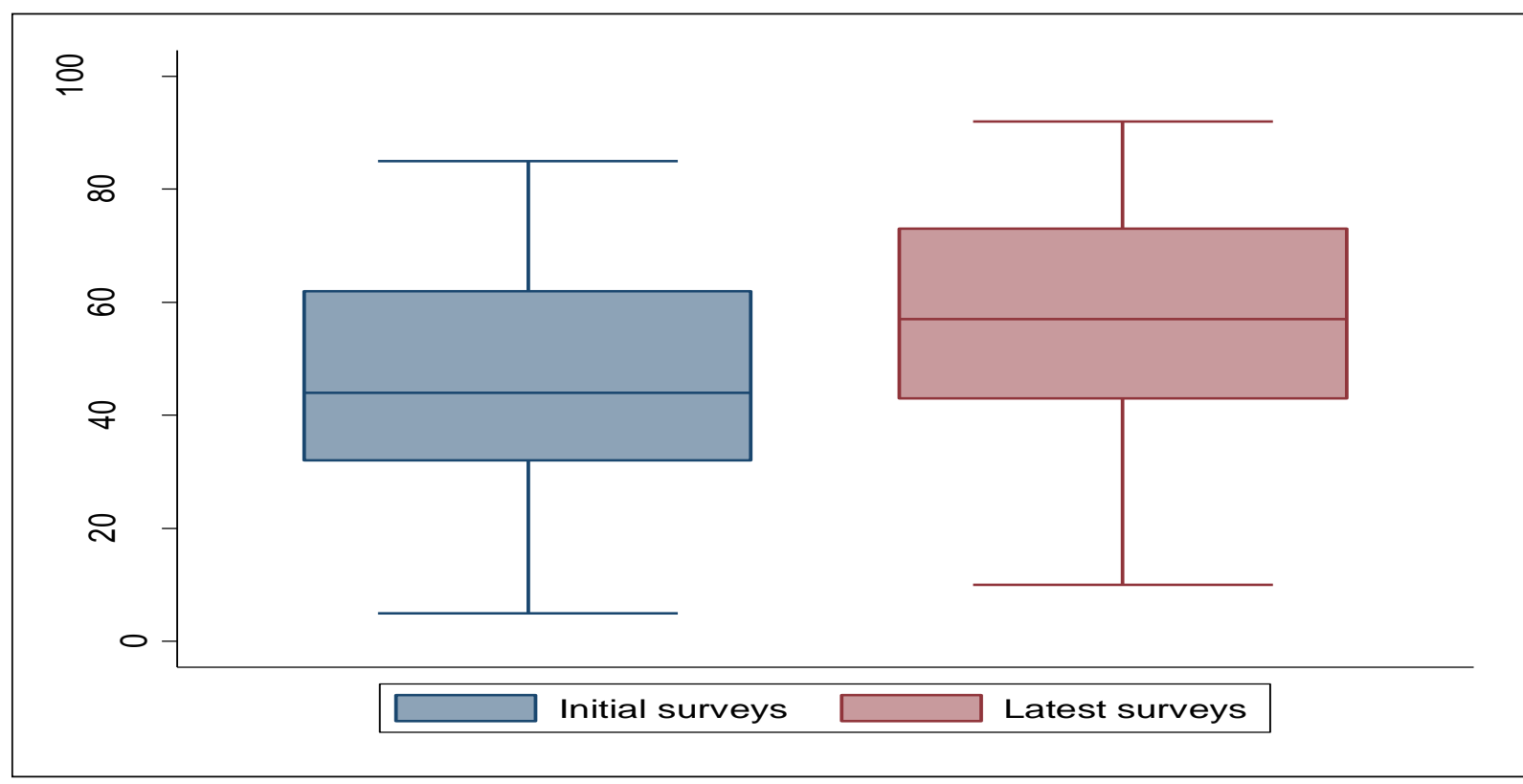

Health facility births were identified by asking women "Where did you give birth to [Name]?" Possible options were "home", "other home", a list of different types of public, private or nongovernmental health facilities (e.g. Government Hospital, Government Health Centre, Private Clinic), and "Other places" that required specification. Analyzing inequity gaps in facility births between the initial and the latest surveys as well as urban-rural inequities is ideal as the SubSaharan African countries join the international community in implementing strategies to meet the Sustainable Development Goals focusing on health by 2030 .

\section{Analysis}

We used the percentage of women who had a recent health facility birth in the earliest and latest surveys and compared if the gap between the two surveys had narrowed or widened. We then examined the urban and rural differences as well as regional variations in the two sets of surveys to establish the direction and magnitude of the difference. Urban-rural disaggregation helps assess the context in which implementation of health policies varies by type of residence. Examining regional variations is ideal as it provides opportunities not only to understand the regional dynamics but also to learn from other countries. We also examined the correlation between NMR and percent of facility births. We related the results of this analysis to the various interventions that had taken place since the 1990s to encourage health facility births in SSA and to map out areas of successes and challenges.

\section{Results}

\section{Facility births at initial and latest surveys}

For all the 27 countries included in the analysis, the median value for facility births increased from $44 \%$ at initial survey to $57 \%$ at the latest survey times representing a 13 percentage point increase (Figure 1). Corresponding average facility births for the 27 countries were almost equal to the median values, at $46 \%$ and $58 \%$, respectively. The country with the highest percentage of facility births at the latest survey was Congo (Brazzaville) at $92 \%$ followed by Gabon at $90 \%$. The lowest percentages of facility births were observed in Chad (13\%) and Ethiopia (10\%) (Figure 2).

Since the absolute changes can mask the real dynamics in that some countries already had highest percentage of facility births at the initial 
Figure 2: Initial and Latest Percentage of Health Facility Births in 27 sub-Saharan African Countries for Surveys Conducted between 1990 and 2015

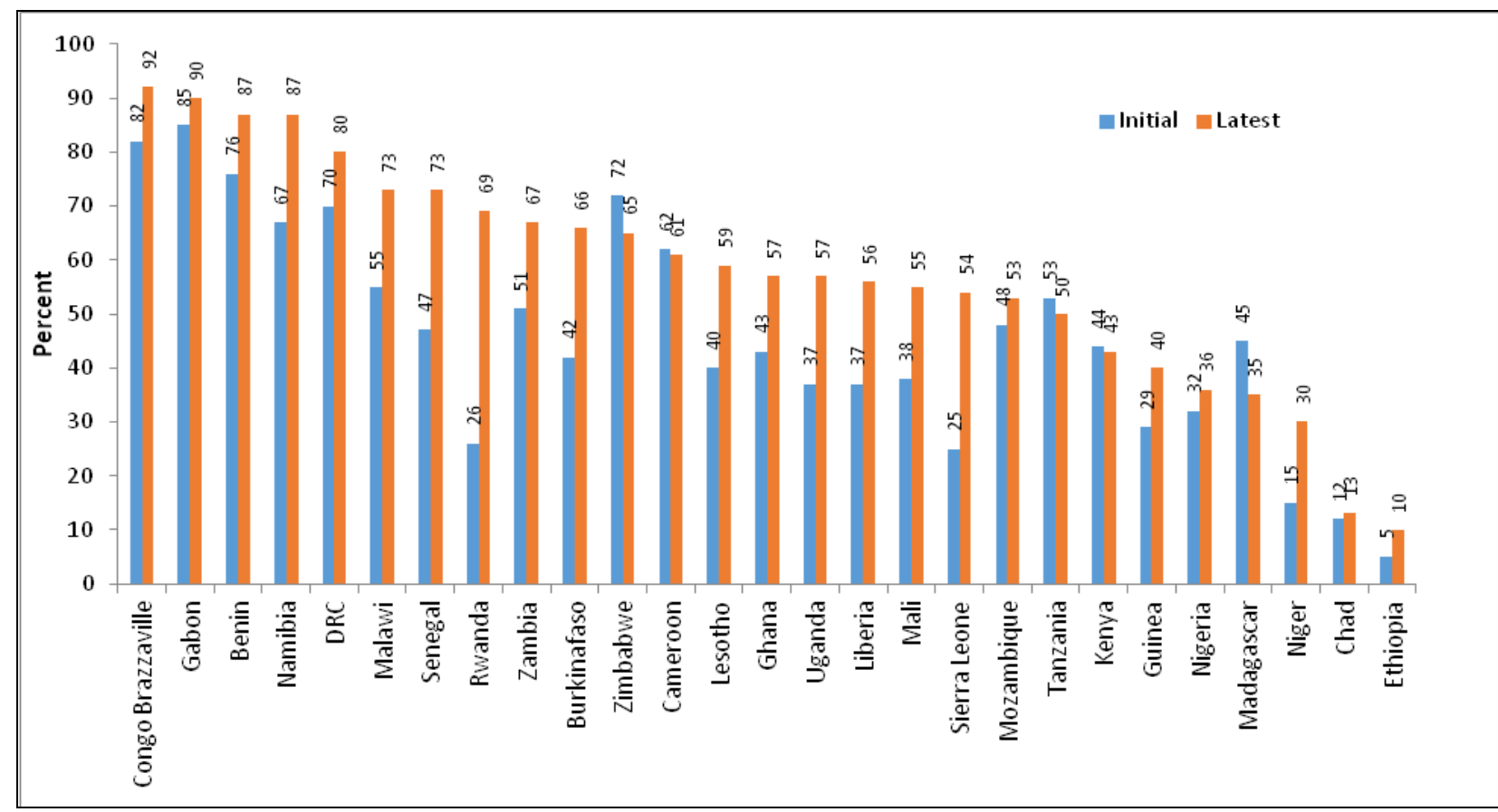

survey, we converted them into percentage changes between the two surveys. Results (Figure 2) show that Rwanda had the highest percentage change at $43 \%$ followed by Sierra Leona (29\%) and Senegal (26\%). Thus, the inequity gap between the leading country (Rwanda) and runner up (Sierra Leona) is 14 percentage points, much higher than the differences between the remaining countries (Figure 1). The lowest percentage changes were observed in Madagascar (-10\%), Zimbabwe (-7\%), Tanzania (-3\%), Kenya (-1\%), and Cameroon (-1\%) (Figure 3).

\section{Urban and rural health facility births at initial and latest surveys}

In terms of urban - rural differences in facility births, rural areas on average had a higher percentage increase in facility births between initial and latest surveys $(16 \%)$ than urban areas $(6 \%)$. However, there were higher facility births in urban areas on average, compared to rural areas. Median urban-rural gap in health facility births at initial survey was $35 \%$ and at latest survey, median urban-rural gap reduced to $33 \%$ indicating a $2 \%$ overall gap reduction across the 27 countries. When gaps between urban and rural areas at initial and latest times are compared by regions, results show that Western Africa had the highest gap (42 $\%$ and $37 \%$, respectively), Eastern Africa (38\% and $36 \%$, respectively), followed by Southern Africa (31\% and $25 \%$, respectively) with Middle Africa at the least (30\% and $24 \%$, respectively). Of all the regions, the smallest gap reduction was in Eastern Africa (2\%) (Figure 4).

When the percentage increases in facility births are compared by regions, results show that Southern Africa had the highest increase at $19 \%$, Western Africa at $18 \%$ followed by Middle Africa at $10 \%$ and the lowest in Eastern Africa at $8 \%$ (Figure 5).

\section{Relationship between facility births and neonatal mortality rates at initial and latest surveys}

The average and median NMRs during the initial survey for all the 27 countries were almost equal at 38.1 and 38.0 deaths per 1,000 live births, respectively. For the initial survey, the lowest and highest NMRs were 26 (Kenya) and 57 (Mali) deaths per 1,000 live births. Health facility births were inversely associated with NMR at initial 
Figure 3: Percentage Increase in Health Facility Births Between 1990 and 2015 for 27 Countries in sub-Saharan Africa

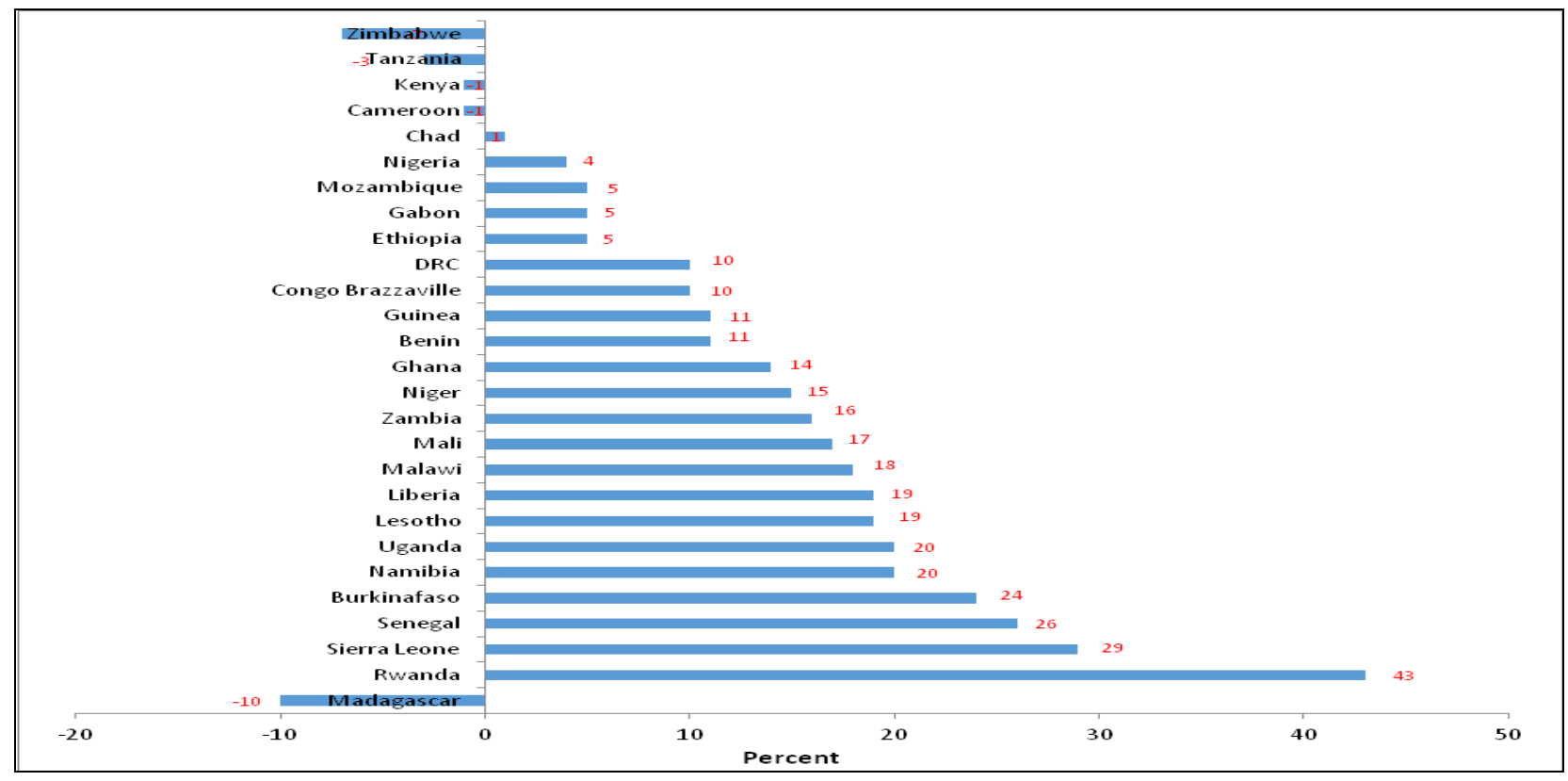

Figure 4: Initial and final Gaps and Gap Reductions in Facility Births Between Urban and Rural Areas by sub-Saharan Africa Region

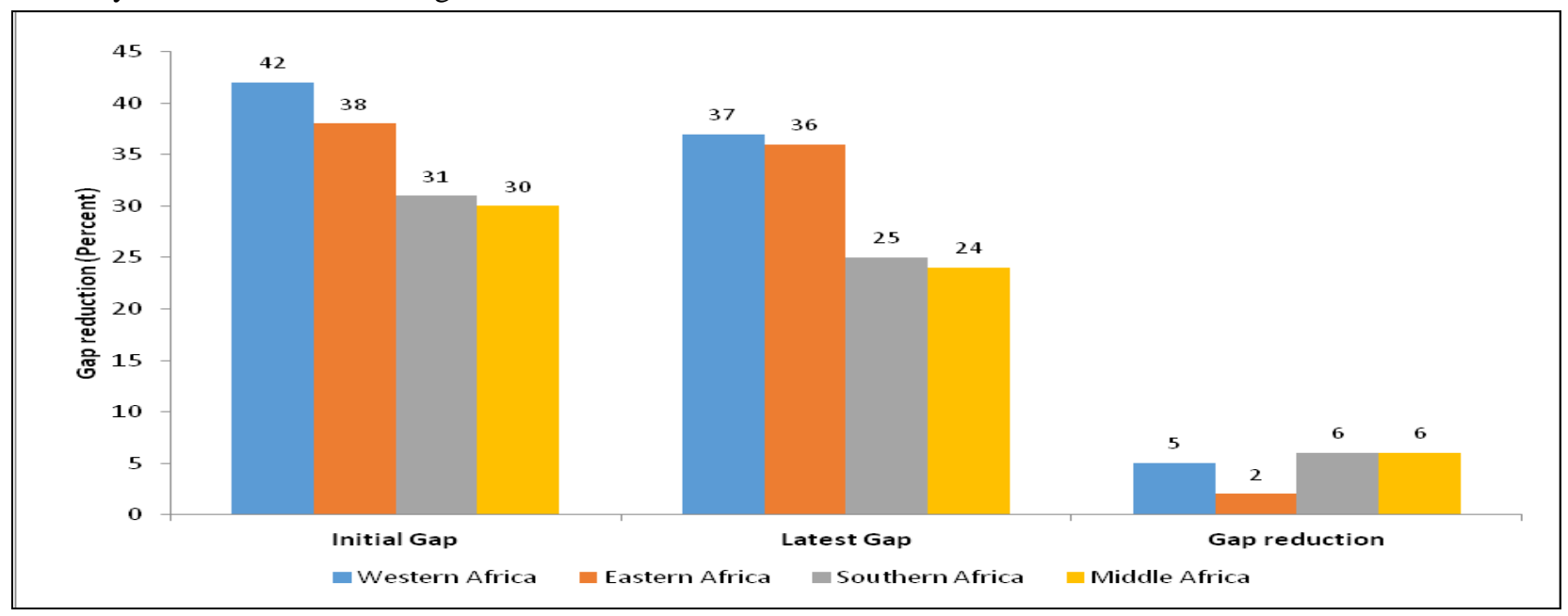

survey times for all the 27 countries $\left(\mathrm{R}^{2}=0.20\right.$, $\mathrm{p}=0.019$ ) (Figure 6). In simple terms, an increase in facility births was associated with a decrease in NMRs. For the latest survey, the average and median NMRs for all the 27 Sub-Saharan African countries were almost equal at 29.4 and 28.0 deaths per 1,000 live births, respectively. For the latest surveys, the lowest and highest NMRs were 19 (Senegal) and 47 (Lesotho) deaths per 1,000 live births. Thus, the gap in NMRs between the initial and latest survey times for all the countries declined by 3 points from 31 deaths per 1,000 live births (Kenya and Mali) to 28 deaths per 1,000 live births (Senegal and Lesotho). Health facility births and NMRs were also inversely related at the latest survey times for all the 27 countries $\left(\mathrm{R}^{2}=0.26, \mathrm{p}=0.007\right)$ (Figure 7).

\section{Discussion}

Our study provides a unique opportunity to critically examine facility births among Sub- 
Figure 5: Percentage of Health Facility Births for the Initial and Latest Surveys and Percentage Increase for subSaharan African Regions

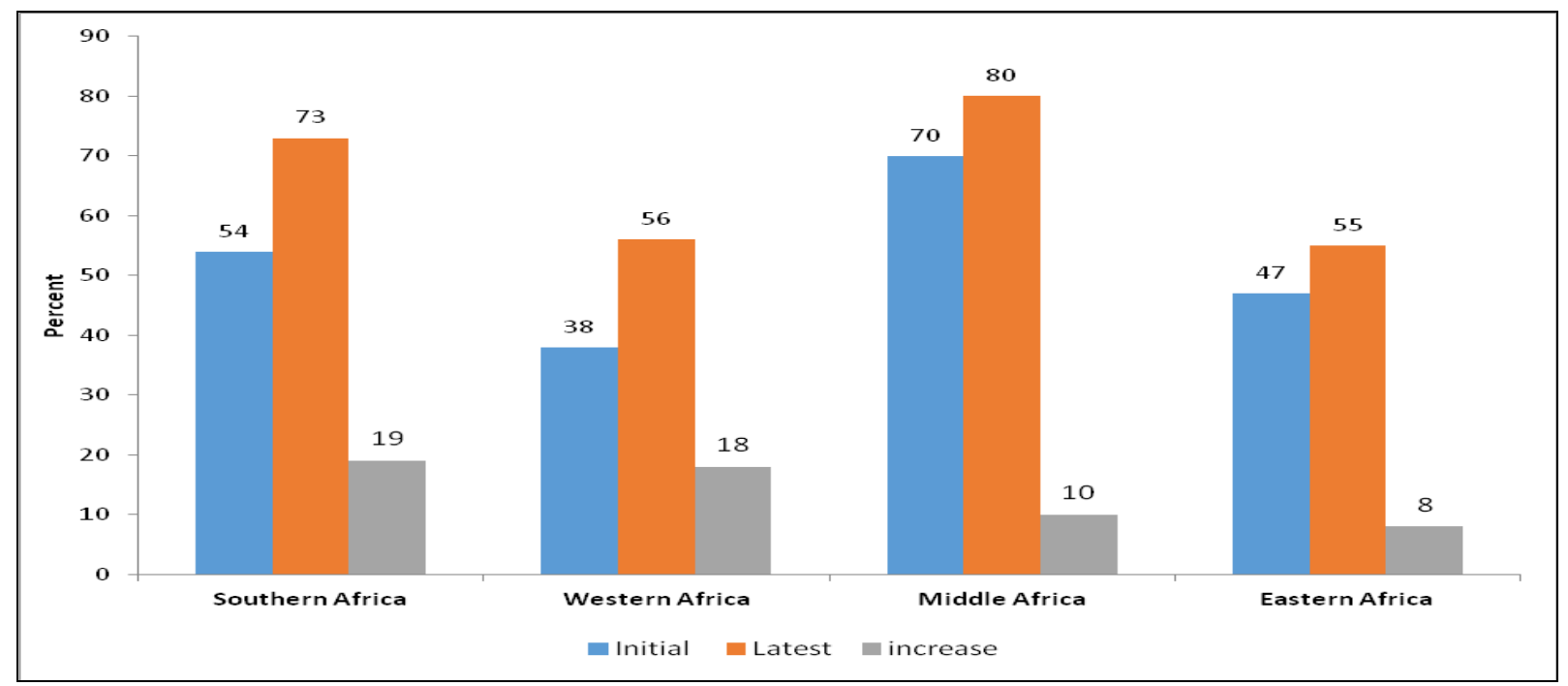

Figure 6: Relationship Between Neonatal Mortality Rates and Facility Births at Initial Survey for 27 sub-Saharan African Countries

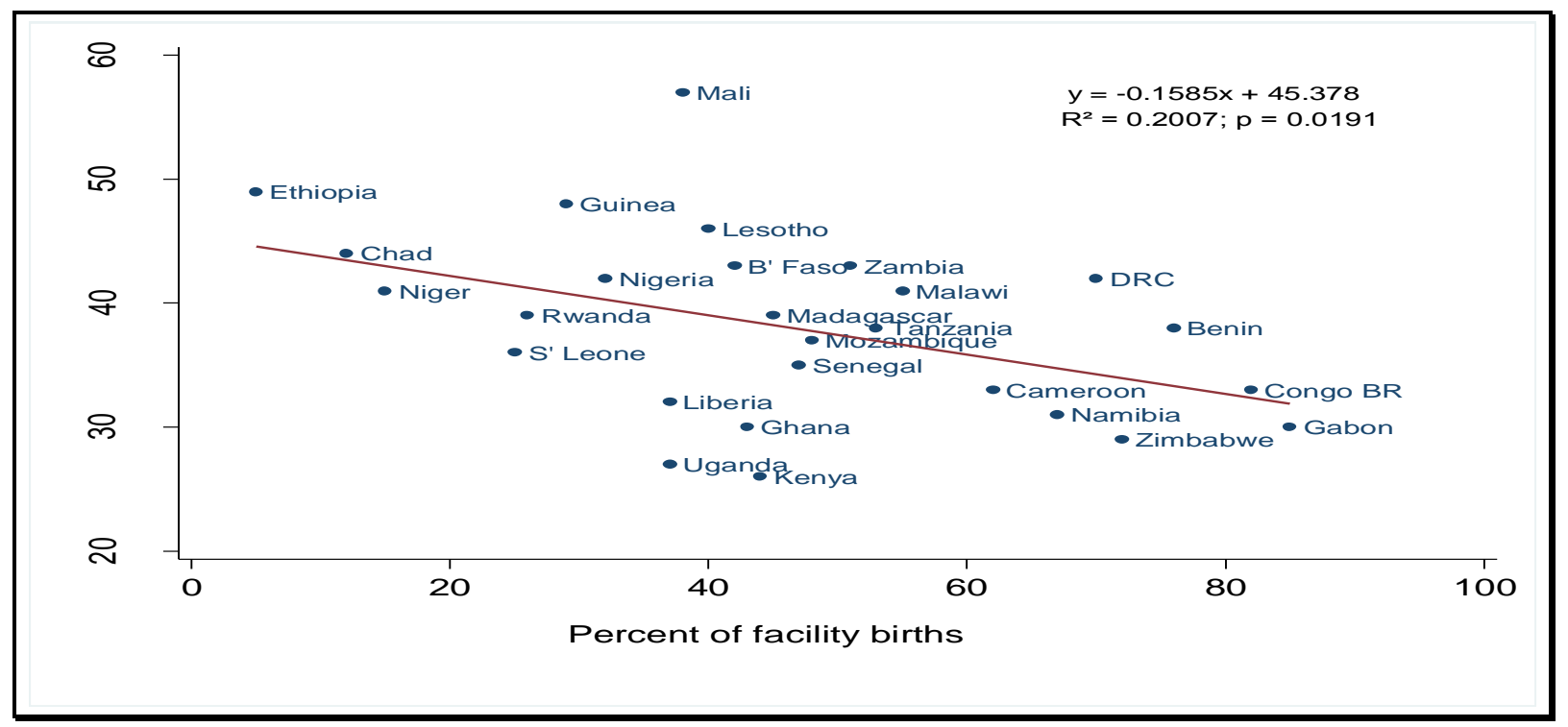

Saharan African (SAA) countries and between urban and rural areas. We found an overall increase in health facility births from levels at initial surveys, although this was mainly driven by health facility births in urban areas. Despite this increase, more than $40 \%$ of births in SSA are not attended by skilled personnel compared to developed countries where $96 \%$ of births are attended by skilled personnel. Effective delivery and postpartum care can reduce preventable maternal and newborn deaths and is enhanced by facility birth, under the care of skilled personnel. With SSA accounting for $47 \%$ of child deaths in 2015, key interventions will reduce the rates of child mortality in SSA countries ${ }^{7}$. Tremendous progress has been made in reducing global mortality, nonetheless, Millennium Development Goal (MDG 4) target of bringing down the rates of child mortality and by two thirds in 2015 , from the 1990 levels was not met ${ }^{22-23}$. In the wake of the new Sustainable Development Goals (SDGs), more ambitious goals have been set for 2030. SDG 


\section{Udo \& Doctor}

3.2 seeks to end preventable deaths of newborns and children under-5 years, with all countries aiming to reduce rates to at least as low as 25 deaths per 1,000 live births including attaining neonatal mortality rates (NMR) of no more than 12 deaths per 1,000 live births. Realizing these targets may be compromised if the current child (and neonatal) mortality trends in SSA continue. Although births under the supervision of skilled personnel have increased globally from $58 \%$ in 1990 to $73 \%$ in 2013, this increase is mainly driven by increases in urban area ${ }^{7}$. Rural areas continue to lag behind. We found the same trend among the 27 countries examined, with urban areas recording more facility births than rural areas. This disparity affects national, regional, and global facility births and skilled birth coverage rates and thus negatively impacts NMRs as well as under-5 mortality. Data from 2005-2013 show that poor people report lower number of births covered by skilled personnel than their wealthy counterparts. Given that rural areas are to a large extent, inhabited by people in the lowest wealth quintile, the issue of coverage by skilled birth personnel and access to health facility is more socially determined ${ }^{7}$. The implication of disparities in skilled birth coverage is direr when we consider that SSA consists of low and middle income countries with lower overall socioeconomic status compared to high income countries, hence impacting coverage by skilled personnel. Our study found that despite the narrowing of the gap in facility births between urban and rural areas at both survey times, rural areas still recorded lower rates at both survey times.

At the regional level, Southern Africa registered the highest increase in facility births followed by Western Africa, Middle Africa, and Eastern Africa. The variations observed in health facility births may be indicative of the differences in cultural, economic, policy and programmatic factors that impact trends in facility births and NMRs. For example, despite having one of the lowest Gross National Income (GNI) per capita (US\$1,290) among the 27 countries, Rwanda registered the highest increase (43\%) in facility births compared to other countries such as Nigeria with GNI per capital that is more than four times

\section{Trends in Health Facility Births in Africa}

higher than that of Rwanda. While cross-country variations in socio-cultural dynamics may compromise delivery of health services - for example, high illiteracy rates and myths about health facility delivery observed in some parts of northern Nigeria ${ }^{24}$,- nonetheless, countries can learn from Rwanda's success story that is characterized by policies focusing on health workforce and infrastructure development, strong community involvement, a comprehensive community-based health insurance, among others $^{25}$. Countries can enact similar policies, while concurrently addressing socio-cultural factors that may impede effectiveness and progress.

Furthermore, we found that the gaps in facility births between urban and rural areas are strongly positively associated with NMR. As this gap widened, NMR increased. To improve NMR and to be on track for achieving the SGD targets for reducing under-5 mortality, the gap in facility births between urban and rural areas must be closed or at best narrowed. Urban and rural areas should enjoy equal access and utilization of skilled personnel during child birth. According to the World Health Organization, 34 out of the 47 countries projected to come short of the proposed SDG target for under-5 mortality (25 deaths per 1,000 live births by 2030) are in SSA. If the current trend continues, these countries may not meet the SDG target until $2050^{8}$.

While proximity to health centers and lack of access may be an important contributor to global maternal mortality and subsequently neonatal and under-5 mortality rates, the least developed countries such as those in SSA are faced with several other challenges such as less standard quality of care, poor sanitation, limited economic opportunity, all of which slow down progress in reducing mortality rates. In addition, culture, beliefs and norms such as gender inequity may contribute to low facility births in SSA, besides proximity and /or lack of access. For example, women may be debarred from using health care services by their husbands and partners; they may also underutilize available maternal and child health services due to cultural beliefs that only weak women use those 
services $^{24,26}$.

Some limitations in our study are noteworthy. First, we did not examine the association between facility births and NMR in a multivariate model and as such we did not control for any extraneous variables. However, given the low p-values and the R-squared values (0.20-0.26) we obtained from our correlation (bivariate) analysis, it is highly unlikely that the strong association we observed can be completely attenuated by controlling for possible extraneous variables. Second, our study used facility birth as an indicator of skilled birth attendance at birth. While we know that there are occasions, when births occurring in health facilities (in SSA) are unattended due to absence of skilled personnel, these events are not typical and we do not think that they occur frequently enough to have any significant effect on our results.

To conclude, our study found an increase in facility births from initial survey to latest survey. However, these rates are still low and insufficient to meet the targets for the SDGs of reducing neonatal mortality rates (NMR) to 12 per 1,000 live births or lower. Aggressive efforts are needed to keep sub-Saharan African countries on track to achieve the SDGs. Given the strong inverse correlation we observed between facility births and NMR, policies focused on increasing access and utilization of maternal and health services is needed in SSA. An important lesson should be learned from Rwanda, where enactment of policies expanding maternal and health services have translated to increased facility births coupled with reduction in NMR over the years. It is also expedient for countries to pay close attention to urban-rural gaps in facility births and neonatal survival outcomes, as they implement these policies. Our trend analysis showed increases in facility births in urban and rural areas, but these did not eliminate the urban-rural gap in facility births. The better countries are able to close this gap, the more feasible it is to achieve the SDG target for infant and neonatal mortality. Furthermore, infections are one of the leading causes of neonatal deaths in SSA. It is important to ensure clean birth environment and sustained hygiene in the postnatal period particularly in rural areas where resources are more limited.
Maternal and child health services should be comprehensive enough to assure the health and wellness needs of women from preconception through pregnancy and postpartum. Furthermore, there is a need to continue to work on other areas such as reducing gender inequity, improving women's economic power and demystifying norms and cultural beliefs around use of health facilities. The MDG targets although not met, have led to impressive progress in maternal and child health indicators but sustained and persistent efforts are needed to maintain this progress. Interventions and services to increase facility births in rural areas need to be increased and strengthened.

\section{Acknowledgments}

We would like to thank the MEASURE DHS Program and the National Statistical Offices of the 27 Sub-Saharan African countries for making the data publicly available with financial support from USAID.

\section{Conflict of Interest}

The authors declare no conflict of interest.The views expressed in this article are those of the authors and should not be taken to represent those of their institutions.

\section{References}

1. Alkema L, Chou D, Hogan D, et al. Global, regional, and national levels and trends in maternal mortality between 1990 and 2015, with scenario-based projections to 2030: A systematic analysis by the UN maternal mortality estimation inter-agency group. Lancet, 2016, 387: 462-474.

2. Stanton C. Steps towards achieving skilled attendance at birth. Bull World Health Organ., 2008, 86, 4: 242242A. doi:S0042-96862008000400002.

3. United Nations. We can end poverty. Millennium development goals and beyond 2015. New York, United Nations, 2013.

4. United Nations. The millennium development goals report 2015. New York, United Nations, 2015:3839-43.

5. World Health Organization. Tracking universal health coverage. First global monitoring report. Geneva, World Health Organization, 2015.

6. UNICEF. Levels and trends in child mortality. 2013 report on estimates developed by the UN interagency group for child mortality estimation. New 


\section{Udo \& Doctor}

York, UNICEF, 2013

7. World Health Organization, Regional Office for Africa. The health of the people: What works - the African regional health report 2014. Brazzaville, World Health Organization AFR), 2014.

8. UNICEF. Levels and trends in child mortality. 2015 Report on estimates developed by the UN interagency group for child mortality estimation. New York, UNICEF, 2015.

9. Jehan I, Harris H, Salat S, et al. Neonatal mortality, risk factors and causes: A prospective population-based cohort study in urban Pakistan. Bull World Health Organ. 2009; 87(2):130-138.

10. Mah-Mungyeh E, Chiabi A, Tchokoteu FL, Nguefack S, Bogne JB, Siyou HH, Tchokoteu PF. Neonatal mortality in a referral hospital in Cameroon over a seven year period: Trends, associated factors and causes. Afr Health Sci, 2014, 14(4), 985-992. doi:10.4314/ahs.v14i4.30

11. West BA, Tabansi PN. Prevalence of neonatal septicaemia on the University of Port Harcourt Teaching Hospital, Nigeria. Niger J Paed, 2014, 41(1), 33-37.

12. Edmond K, Zaidi A. New approaches to preventing, diagnosing, and treating neonatal sepsis. PLoS Medicine, 2010, 7(3), e1000213. doi:10.1371/ journal.pmed.1000213.

13. Ojukwu JU, Abonyi LE, Ugwu J, Orji IK. Neonatal septicemia in high risk babies in south-eastern Nigeria. J Perinat Med, 2006, 34(2), 166-172. Doi :10.1515/JPM.2006.030.

14. Bhutta ZA, DarmstadtGL, Hasan BS, Haws RA. Community-based interventions for improving perinatal and neonatal health outcomes in developing countries: A review of the evidence. Pediatrics, 2005, 115(2 Suppl), 519-617. doi: 115/2/S1/519.

15. Prata N, Passano P, Rowen T, Bell S, Walsh J, Potts M. Where there are (few) skilled birth attendants. $J$ Health Popul Nutr. 2011; 29(2):81-91.

16. Kyei-Nimakoh M, Carolan-Olah M, McCann TV. Barriers to obstetric care at health facilities in subSaharan Africa--a systematic review protocol. Syst Rev. 2015;4:54-015-0045-z.

\section{Trends in Health Facility Births in Africa}

17. Wang W, Alva S, Wang S W, Fort A. Levels and trends in the use of maternal health services in developing countries. Calverton, Maryland, ICF Macro, MEASURE DHS, 2011.

18. Adebowale SA, Udjo E. Maternal health care services access index and infant survival in Nigeria. Ethiop $J$ of Health Sci, 2016, 26(2):131-144.

19. Dahiru T, Oche OM. Determinants of antenatal care, institutional delivery and postnatal care services utilization in Nigeria. Pan Afr Med J, 2015, 21, 321. doi:10.11604/pamj.2015.21.321.6527.

20. Moyer CA, Mustafa A. Drivers and deterrents of facility delivery in sub-Saharan Africa: A systematic review. Reprod Health, 2013, 10, 40. doi:10.1186 /1742-4755-10-40.

21. Crowe S, Utley M, Costello A, Pagel C. How many births in sub-Saharan Africa and south Asia will not be attended by a skilled birth attendant between 2011 and 2015? BMC Pregnancy Childbirth. 2012; 12:4-2393-12-4.

22. World Health Organization. Trends in maternal mortality: 1990-2015. Estimates by WHO, UNICEF, UNFPA, World Bank Group and the United Nations Population Division. Geneva, World Health Organization, 2015.

23. Bhutta ZA, Black RE. Global maternal, newborn, and child health--so near and yet so far. $N$ Engl J Med. 2013; 369(23):2226-2235.

24. National Population Commission (NPC) [Nigeria] and ICF International. Nigeria Demographic and Health Survey 2013. Abuja, Nigeria, and Rockville, Maryland, USA: NPC and ICF International, 2014.

25. Worley H. Rwanda's success in improving maternal health. Population Reference Bureau Web site. http://www.prb.org/Publications/Articles/2015/rwan da-maternal-health.aspx. Published February 2015. Updated 2015. Accessed January, 18, 2015.

26. Doctor HV, Findley SE, Ager A, et al. Using community-based research to shape the design and delivery of maternal health services in northern Nigeria. Reprod Health Matters. 2012; 20(39):104112. 